\title{
Unas palabras en honor al Profesor Albert L. Rhoton Jr
}

Con gran honor y respeto es que escribo los siguientes párrafos en memoria del Dr. Albert L. Rhoton Jr, quien falleció el pasado 21 de febrero en Gainesville, Estados Unidos, víctima de un cáncer que lo aquejó por largo tiempo. Es realmente difícil resumir en parte sus numerosos logros y destacadísima carrera como neurocirujano y docente. Será recordado probablemente como el "padre de la neurocirugía microscópica moderna".

Nació el 18 de noviembre de 1932 en un humilde hogar en Kentucky. Posteriormente se trasladó junto a su familia a Ohio donde entró al colegio. Fue en trabajos part-time mientras estudiaba en la Universidad de Ohio que compartió con niños vulnerables en lo socioeconómico, lo que lo motivó a estudiar trabajo social. Fue en una clase de psicología de ésta carrera, donde conoció los misterios y belleza del cerebro humano. Este hecho sería la razón por la cual estudiaría neurocirugía posteriormente. Luego de graduarse de trabajo social, estudió medicina en la Universidad de Washington graduándose con los más altos honores en 1959. Completó su residencia de neurocirugía en la misma Universidad y posteriormente realizó un research fellow en neuroanatomía en el National Institute of Health a cargo del Dr Henry Schwartz. En 1966 se unió como staff de neurocirugía a la Clínica Mayo. Fue en 1972 cuando dejó el servicio de la Clínica Mayo y se trasladó como jefe de servicio a la entonces pequeña unidad de neurocirugía de la Universidad de Florida, en Gainesville, compuesta por sólo dos neurocirujanos. La unidad creció y se convirtió en lo que es actualmente, un departamento de neurocirugía con un total de 18 neurocirujanos, 13 research faculty y un total de 21 residentes. En 1975 inició una serie de cursos de microcirugía en la Universidad de Florida a los que han asistido más de 1.000 neurocirujanos y residentes de todo el mundo. Publicó más de 500 trabajos científicos, numerosos capítulos de libros y tres libros, destacando dentro de ellos "Rhoton's Cranial Anatomy and Surgical Approaches", un verdadero best seller de la neurocirugía contemporánea.

En sus más de 5 décadas de enseñanza entrenó a miles de neurocirujanos alrededor del mundo, más de 50 residentes de neurocirugía completaron su especialidad mientras él fue jefe de servicio y cerca de 100 research fellows trabajaron con él en su laboratorio de microcirugía. Desarrolló cientos de productos e instrumental de microcirugía inexistentes hasta ese momento y recibió las más altas distinciones de la neurocirugía mundial, incluyendo la medalla Cushing de la asociación americana de neurocirugía (AANS) y la medalla de honor de la federación mundial de sociedades de neurocirugía (WFNS), por mencionar sólo algunas. Probablemente su gran aporte a nuestra profesión fue el desarrollo de la neurocirugía microquirúrgica. Incorporó el uso del microscopio a la cirugía, demostró la microanatomía involucrada en los distintos abordajes y fue pionero en el desarrollo de instrumental de microcirugía, muchos de los cuales llevan su nombre, y sin los cuales varios de nosotros probablemente no operaríamos actualmente una patología de base de cráneo. El objetivo de esto según él mismo decía era hacer de la cirugía un proceso más "accurate, gentle and safe".

En lo personal, tuve la oportunidad de trabajar junto a él y su equipo durante poco más de un año en su laboratorio de microcirugía ubicado en el Mc Knight Brain Institute, de la Universidad de Florida, en Gainesville, Estados Unidos. El Dr. Rhoton o también Professor como cariñosamente nos referíamos a él -los research fellows- destacó siem-

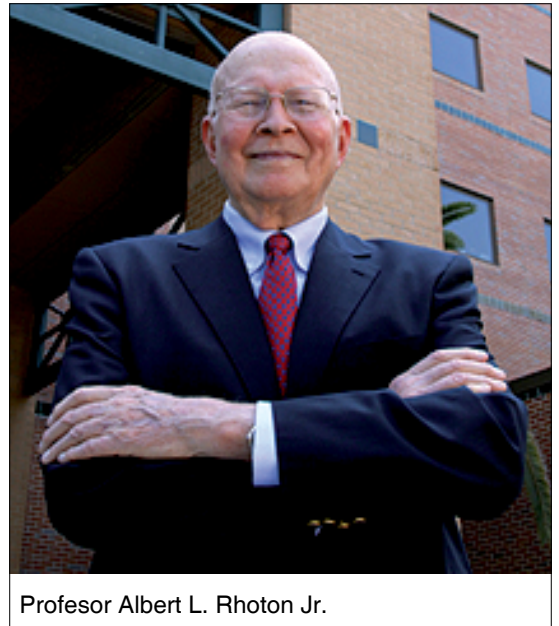

pre por su humilde personalidad y gentil forma de ser. No importaba cuántas veces le hicieran una pregunta, el Dr. Rhoton siempre se daba el tiempo de explicarle a sus alumnos. Era sin embargo, muy exigente en lo que a disecciones se refería y siempre consideraba que algo podía hacerse mejor. Una imagen -decía- vale más que mil palabras. Supervisaba personalmente cada uno de los proyectos de los research fellows, proponía disecciones anatómicas y corrigió hasta el último día los manuscritos que realizaban sus alumnos.

No sólo se preocupaba del trabajo realizado en el laboratorio, sino que también de la adaptación del resto de la familia que acompañaba al fellow durante su estadía en Gainesville.

Tuve además la inigualable oportunidad de escuchar directamente del Dr. Rhoton sus clases de neuroanatomía en 3D a las que asistían regularmente los residentes del departamento de neurocirugía. Un detalle de la prolijidad con que preparaba sus clases y que nunca olvidaré, era que para cada clase que dictaba le solicitaba a la secretaria del servicio que dispusiera de an- 
teojos nuevos para la audiencia. Esto con el fin de que la nitidez de la imagen y el efecto 3D fuera perfecto.

El resultado del trabajo realizado en su laboratorio es probablemente conocido por muchos de ustedes a través de las fotografías de sus distintos artículos científicos. Sin embargo, el trabajo que una disección cadavérica implica es probablemente desconocido. El proceso de preparación de los especímenes cadavéricos, lavado, inyección, disección y posterior registro fotográfico es tremendamente laborioso. El Dr. Rhoton decía que recién después de seis meses de intenso trabajo en el laboratorio, el research fellow estaba en condiciones de realizar disecciones anatómicas de calidad. Mi caso no fue la excepción.....

No puedo dejar de mencionar la gran gentileza de Professor, su esposa
Joyce, su hija Alice, su nieto Alexander y su familia en general con todos nosotros. Cada vez que un research fellow terminaba su estadía en el laboratorio o bien, uno nuevo llegaba, era tradición reunirse en su hogar para compartir una pizza y beber una cerveza. Era entonces cuando él por ejemplo, señalándonos unas fotografías de su casa nos comentaba que había conocido personalmente al ex presidente Jimmy Carter o bien, su esposa Joyce nos ofrecía su delicioso pastel de calabazas.

El espíritu docente del Dr. Rhoton estimulaba a todos a su alrededor y como parte de nuestro compromiso con él, espero poder fomentar el estudio de la neuro microanatomía en mi país, continuando la labor en distintos cursos de capacitación de la especialidad y en especial con el desarrollo de un laboratorio de neuro microanatomía que es- pero esté a la altura de sus exigencias y del que pudiese estar orgulloso.

Aprovecho esta oportunidad para agradecerle sinceramente a todos quienes me ayudaron y con quienes compartí durante mi estadía en Gainesville. Al Profesor Rhoton por supuesto, los ilustradores médicos Robin Barry y David Peace, las secretarias Laura Dickinson y Jessica Striley, mis amigos y colegas fellows Eduardo Ribas, Thomas Frigeri,, Leila da Roz, Noritaka Komune, Ken Matsushima, Kaan Yagmurlu y en especial a mi esposa María Teresa Donoso, quien con su amor y apoyo incondicional hizo de nuestra estadía en Gainesville un hermoso recuerdo.

God bless you Professor

Dr. Tomás Poblete Poulsen 